\title{
Los himnos criptográficos de la tumba de Djehuty (TT 11). Posibles funciones y contextos
}

Andrés DIEGO ESPINEL

En el patio de la tumba de Djehuty (TT 11) se encuentran los dos himnos en escritura criptográfica más antiguos que se conocen y que están siendo estudiados actualmente por el autor dentro del marco del "Proyecto Djehuty". En el presente trabajo se analiza su contenido y, sobre todo, sus posibles funciones y contextos tanto en la tumba como en el ámbito cultural de la elite en el que se crearon: aquél del reinado conjunto de Tutmés III-Hatshepsut. Dicho estudio muestra que tanto en su forma como en su contenido los himnos están en estrecha conexión con el Zeitgeist de ese período - marcado por un equilibrio entre tendencias arcaizantes e innovadorasy con la manifestación, a través del ingenio y la originalidad, de las capacidades del propietario de la tumba.

The cryptographic hymns of the Tomb of Djehuty (TT 11). Possible functions and contexts

The oldest Egyptian cryptographic hymns are located in the courtyard of the tomb of Djehuty (TT 11). The present study analyzes their contents, currently under study by the Spanish mission working at Dra Abu el-Naga (TT 11), and particularly their functions and contexts within the tomb and in the elite cultural circles where they were composed during the joint reign of Thutmoses III-Hatshepsut. Their themes and forms of expression indicate that these hymns were closely related to their contemporary Zeitgeist -marked by a balance between archaizing and innovative trends-and the reflection, by means of personal originality and wit, of the intellectual capacities of the tomb owner.

KeY wORDs: Thebes, $18^{\text {th }}$ Dynasty, cryptography, cultic hymns, Hatshepsut, Djehuty

$\mathrm{E}$ 1 presente artículo, enmarcado dentro del "Proyecto Djehuty" dirigido por José Manuel Galán (CSIC), tiene como objeto, por un lado, ofrecer un estudio preliminar -y provisional- sobre los contextos que inspiraron la creación, tanto en el contenido como en la forma, de los textos criptográficos inscritos en el patio de la tumba o capilla funeraria de Djehuty así como los diferentes papeles que pudieron desempeñar en ella. Por otro, pretende emplazarlos dentro de la cultura de la elite cortesana egipcia durante la primera mitad de la dinastía XVIII. Este trabajo, por tanto, no es un análisis filológico de los tex- tos, aún en proceso de estudio, sino sólo un breve ensayo sobre el panorama cultural en el que se crearon y manifestaron.

\section{Contexto espacial de los teXtos}

Las composiciones estudiadas en este trabajo fueron inscritas en la capilla funeraria de Djehuty, supervisor del tesoro durante el reinado conjunto de Tutmés III-Hatshepsut, que está situada en Dra Abu el-Naga, en la orilla occidental de Tebas. ${ }^{1}$ El monumento, aprovechando un delgado estrato de

1. Sobre la tumba y sobre las excavaciones y estudios que se están realizando actualmente en ella por la misión española del "Proyecto Djehuty", véase: PM I² 21-24 (los hallazgos reseñados para la tumba proceden en realidad de la tumba menfita de un contemporáneo homónimo); Galán, 2006; Galán, 2007; y la página web www.excavacionegipto.com.

Fecha de recepción: 9 de enero de 2007

Fecha de admisión: 25 de junio de 2007 
caliza de buena calidad, aunque con numerosas fracturas, está decorado en su totalidad con relieves e inscripciones que, según su posición, han sufrido con mayor o menor fortuna las inclemencias del tiempo y de los hombres.
Los textos criptográficos se encuentran en el patio de la capilla. Concretamente, según la orientación ideal de las sepulturas egipcias, están en el extremo occidental del lado sur del patio (fig. 1)². Se hallan, por tanto, haciendo ángulo con
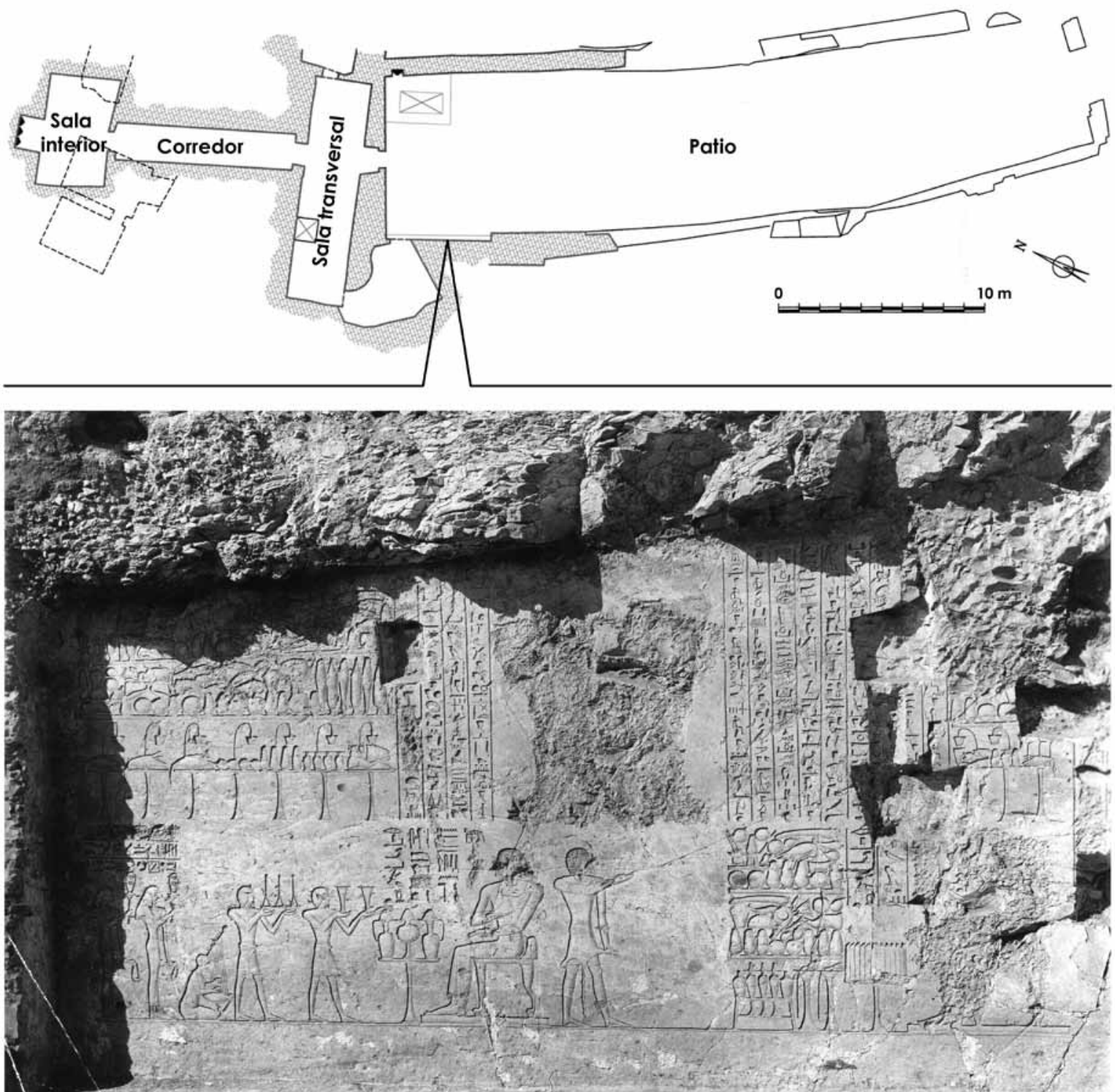

Figura 1. Los himnos criptográficos: situación y disposición. Plano de la capilla funeraria de Djehuty y de su patio indicando el lugar donde se encuentra el panel donde se inscribieron. En la fotografia, tomada en torno a 1910, los textos se sitúan en el friso superior, en sendas escenas separadas por un gran espacio donde se perciben dos figuras canceladas de Djehuty (fotografia Gardiner Mss AHG/28.561, cortesía del Griffith Institute, Oxford)

2. Para el patio y las excavaciones realizadas en él, véase el artículo de Galán en este volumen. 
la fachada de la tumba formada, siguiendo una composición simétrica en torno a la puerta, por la llamada "estela de Northampton" de contenido biográfico y otra estela con un himno, por desgracia muy dañado, dedicado a Amón-Re ${ }^{3}$. Este conjunto de inscripciones y escenas, junto a una estatua en la pared norte y un nicho en la pared sur aún por excavar y que bien pudo contener otra escultura o estela, se encuentran en el exterior del monumento o, en otras palabras, en su parte más pública. Esta circunstancia es de gran importancia para intentar desentrañar su función ya que son muy pocas las tumbas tebanas de este período que, dentro de su programa iconográfico, incluyeron una decoración exterior tan profusa y original como la realizada para Djehuty.

Los textos criptográficos forman parte de un panel inciso bastante elaborado en una amplia superficie rehundida de la pared sur. En ese espacio, dividido en varias escenas diferentes, los textos están emplazados en su parte superior en forma más o menos simétrica. Ambos están precedidos por varias mesas de ofrendas y están seguidos por sendas figuras de Djehuty, estante y en la pose- $i 3 w$ de oración, que, como toda imagen y mención conocida de este personaje, sufrieron damnatio memoriae.

\section{ESTUDIOS PREVIOS DE LOS TEXTOS CRIPTOGRÁFICOS}

El único estudio en profundidad de estas inscripciones es aquél de Kurt Sethe ${ }^{4}$ que, en forma de apéndice, fue incorporado a la memoria publicada en 1908 por el Marqués de Northampton sobre sus excavaciones en Tebas en 1898-1899. El trabajo, uno de los primeros realizados sobre textos criptográficos del Reino Nuevo, sólo incluyó su traducción, no entrando en consideraciones sobre su valor y significado. Pese a ello, para su época, esas páginas son dignas de atención. La traducción realizada por el alemán de uno de los himnos, el denominado aquí como "ctónico", apenas tiene errores gracias, en parte, al hecho de que en él se incluyen, como se verá, pasajes de Los textos de las Pirámides de los que Sethe era un reconocido especialista. En el otro texto, el "himno solar", sin embargo, la lectura es menos certera y se observan numerosas dudas y errores debido en gran parte a su originalidad, brevedad $y$, también, a una importante laguna en su inicio.

El estudio de Sethe y las láminas que lo acompañan muestran ciertas contradicciones entre lo que los excavadores encontraron, lo que el alemán vio y lo que se dibujó y publicó. En una fotografía incluida en la publicación del Marqués de Northampton, se observa que los himnos se conservaban en buen estado justo después de su exhumación. Sin embargo, en el dibujo que acompaña al trabajo y, también, en la trascripción y transliteración que incluyó en él (ambos, a su vez, no coincidentes) se echan de menos diferentes partes de las inscripciones perceptibles en la foto o se documentan otras ilegibles en aquél. Tal diferencia es posible que fuera debida tanto a que Sethe pudo copiar los signos indirectamente (lo cual explicaría que no llegara a leer y dibujar la quinta columna, muy corta, del "himno solar") como, también, a la temprana desaparición de algunas partes de los himnos debido a su extracción por ladrones aprovechando que se trataba de bloques independientes adheridos a la pared por mortero que, aún hoy, todavía es perceptible en sus huecos.

3. Para estos documentos, véase Urk. IV 419, 13-431, 4 (136); 444, 10-447, 17 (137), respectivamente. Ambas copias presentan incorrecciones respecto al original. Véase, para la "estela de Northampton", de Diego Provencio, 2003.

4. Sethe, 1908: $3 *-12 *$; láms. X (fotografia), XI (dibujo).

5. Esa extracción de los bloques fue realizada en un momento impreciso entre la exhumación de la pared, en el invierno de $1898 / 1899$ y 1910 , momento en que el exterior de la tumba fue cubierto a expensas de Sir Alan H. Gardiner para su protección por los daños sufridos en su decoración exterior. Un fragmento de uno de esos relieves (DAN-TT11/12-03/13/215H00-1), en muy mal estado de conservación, fue encontrado por el "Proyecto Djehuty” en la campaña de 2003. 
Es curioso que los textos nunca fuesen estudiados por el más destacado criptólogo de la escritura egipcia, Etienne Drioton (1889-1961). En su artículo sobre la criptografía privada del final de la dinastía XVIII, publicado en 1933, el francés, calificando el trabajo de Sethe como "magistral", reconocía no haber podido abordar una traducción propia ante la ausencia de una buena reproducción fotográfica de las inscripciones ${ }^{6}$. Este hecho, la dificultad que supone abordar ese tipo de textos y, también, su publicación en una monografía no demasiado conocida, han hecho que los himnos no hayan sido objeto de ningún análisis reciente y que, hasta el momento, no hayan sido recogidos en ninguna de las antologías o selecciones de himnos religiosos egipcios como las de Assmann o la de Barucq y Daumas?.

\section{LOS HIMNOS: DESCRIPCIÓN DE SU CONTENIDO}

El contenido de los textos, escritos en la criptografía denominada como "ordinaria" o "normal" , está en estrecha relación con su orientación dentro de la pared donde se inscribieron y con las escenas asociadas directamente a ellos. El llamado "himno solar", el más exterior de los dos, y la figura de Djehuty que lo acompañaba y que aparece tras él, miran hacia el oriente ideal de la capilla indicando de este modo su contenido. Se trata de una pequeña alabanza dedicada a Re en su barca solar. Pese a su brevedad y a las abundantes lagunas y dificultades de lectu- ra -la inscripción aún está en proceso de estudio-, parece aludir tanto al viaje del sol por el cielo como, también, por debajo de la tierra. En él se citan algunos epítetos como "el de turquesa (mfk3ty)" o "quien sale de Kenset (prw m knst)", así como una referencia a "los de la turquesa" que evoca, como se verá más abajo, composiciones religiosas muy significativas. Su parte final se cierra con un "cada (vez) que iluminas el Nun no hay nadie que se oponga a ti (por) tus seguidores y (porque) yo soy un seguidor de Re en el Nun", sobre cuya importancia se volverá más adelante. En conjunto, todo el texto parece resaltar el carácter de regeneración, tanto en el alba como en el peligroso pero siempre exitoso viaje por el mundo subterráneo, de la divinidad solar y, por extensión, del difunto.

La segunda inscripción, más cercana a la fachada, mira, como la figura de Djehuty que lo acompañaba, hacia el interior de la capilla funeraria indicando su contenido. Se trata, de este modo, de un "himno ctónico" dedicado a Osiris. Esta composición, más extensa que la anterior, está formada por nueve columnas. Las siete primeras están dedicadas a Osiris y están formadas por la consecución de diferentes pasajes de Los textos de las Pirámides que resaltan los pasos necesarios realizados para la resurrección de dicho dios (y con ello, como en el himno solar, del difunto $)^{9}$. La parte final, más original, se refiere a otra divinidad ctónica, Ptah, a la que Djehuty se dirige diciendo: "deseo que atiendas mis ple-

6. Drioton, 1933: 2, n. 2.

7. Assmann, 1983; Assmann, 1999; Barucq y Daumas, 1980.

8. Para este tipo de criptografía, véanse Drioton, 1934: 10-13; Drioton, 1953; Darnell, 2004: 1-13. Este sistema sigue los mismos mecanismos de la escritura jeroglífica, esto es, el uso combinado de fonogramas, logogramas y semagramas, pero sustituyendo los signos convencionales por otros nuevos basados, entre otros mecanismos, en la alteración de su apariencia habitual, emplazamiento de unos jeroglíficos por otros similares, empleo de técnicas de rebus, pars pro parte, pars pro toto, y totus pro parte, inversión o "perturbación" en el orden de la escritura, o utilización del principio consonántico, del acrofónico, de la sustitución, etc.

9. La secuencia precisa de los pasajes, siguiendo la división de Sethe, es TP $835 \mathrm{a}-\mathrm{c}+1627 \mathrm{a}-1630 \mathrm{~d}+776 \mathrm{~b}$. Cada pasaje está unido al siguiente por algunas palabras no incluidas en ese corpus religioso. Para un estudio -poco detalladosobre esta secuencia de textos en la tumba, véase Kahl, 1996. 
garias (que dirijo) a ti (porque) tú respondes ante lo que se te ha dicho. Aleja el alba de Sejmet en lo que tenga que ver conmigo. Me uno a estas plegarias de tus seguidores que viajan (por) los caminos del oeste/del cielo".

\section{El CONTEXTo CUltural de LOS himnos}

La función e importancia de estos textos pueden analizarse en tres contextos diferentes pero relacionados entre sí: el religioso, el formal o "artístico-gráfico" y, finalmente, el funcional.

\section{EI ámbito religioso}

Los himnos de Djehuty ilustran bien varios aspectos de la cultura egipcia en general y, más concretamente, de aquélla que se gestaba a comienzos de la dinastía XVIII. Ambos textos son, cada uno a su modo, un buen ejemplo de uno de los rasgos más definitorios de la civilización faraónica a lo largo de su historia: su atavismo o, mejor dicho, su tendencia arcaizante, casi misoneísta ante ojos no expertos, dentro de un continuo, aunque bien disimulado, proceso de transformación y enriquecimiento con nuevas ideas y formas de expresión. La presencia en ambos himnos de referencias tales como "los de la turquesa" o el topónimo Kenset, de la temática del viaje solar o de la secuencia de pasajes de Los textos de las Pirámides muestra que ambas composiciones se inspiraron en obras antiguas como dicho corpus o el de Los textos de los Sarcófagos. También, como sucede en el caso del "himno solar", es perceptible su conexión en la forma y contenido con obras contemporáneas creadas por y para el ámbito religioso más oficial: aquél de los santuarios reales. Así, esa obra guarda similitudes y evoca composiciones tales como El tratado teológico, El libro de la noche, el himno de Los babuinos que anuncian a Re o El ritual de las horas que fueron incluidas dentro del "complejo solar" del templo de "millones de años" de Hatshepsut en Deir el-Bahari y también, en el caso del último texto, en el de Tutmés III ${ }^{10}$.

Todos estos guiños al pasado y a composiciones oficiales contemporáneas también ilustran otra característica importante de la cultura de la elite egipcia a lo largo de su historia: la expresión, de forma más o menos explícita, del acceso por parte de sus miembros de ciertas áreas de conocimiento restringido a la realeza o a los ámbitos más profundos de la religión oficial ${ }^{11}$. Los ejemplos al respecto son numerosos. Basta, por tanto, citar aquí algunas de sus muestras más significativas. Es el caso del uso en la capilla funeraria de Puyemre de varios pasajes de Los textos de las Pirámides y Los textos de los Sarcófagos de forma similar a como se emplearon en el templo de Hatshepsut en Deir el-Bahari. Un ejemplo aún más espectacular es la cámara sepulcral de uno de los monumentos funerarios de Useramón (TT 61), visir durante este período, que se decoró con la Sonnenlitanei o Letanía solar y El Amduat, composiciones restringidas, salvo esta excepción, a las tumbas reales ${ }^{12}$.

La forma en que finalizan los himnos de Djehuty muestra, por otro lado, una tendencia de la religión egipcia que sólo se manifiesta de forma esporádica en la documentación egipcia antes del Período de Amarna: la piedad o religiosidad

10. Sobre los textos religiosos en Deir el-Bahari, véanse Naville, 1901: láms. 114-116; Karkowski, 2003: 157-224; para el procedente del templo de Tutmés III, véase Ricke, 1939: láms. 8-9.

11. Sobre este aspecto, véase Baines, 1990.

12. Para Puyemre, véanse Davies, 1923: lám. 50; Louant, 2000: 91-92; para Useramón, véase Hornung en Dziobek, 1994 : 42-47, láms. 9-16; 28-35. 
personal ${ }^{13}$. Este fenómeno, subyacente a lo largo de la historia de Egipto, muestra en las inscripciones de Djehuty dos ejemplos bastante explícitos. Si las dos escenas en donde se incluyen estos textos sugieren tal piedad al aparecer el propietario adorando con mesas de ofrendas tanto al sol naciente como a las divinidades ctónicas, el final de las dos composiciones acaban confirmando tal intención claramente aunque de forma diferente. En el "himno solar" Djehuty se define como un "seguidor de Re en el Nun" y se proclama partícipe de la victoria del sol sobre el caos. En el "himno ctónico", Djehuty no sólo aparece como ayudante de la divinidad ("me uno a estas plegarias de tus seguidores que viajan (por) los caminos del oeste/del cielo") sino, también, como un peticionario de los favores de Ptah, a quien acude porque "respondes ante lo que se te ha dicho" para que le aparte "del alba de Sejmet", esto es, de todo lo amenazante, sobre todo en los días críticos, los epagomenales, del paso de un año a otro.

Queda por último indicar que el "himno solar" es uno de los primeros ejemplos del creciente fenómeno de "solarización" de la religión egipcia que ha estudiado Assmann ${ }^{14}$. Esa tendencia, que alcanzaría sus límites extremos bajo el reinado de Ajenatón, comienza a manifestarse de forma explícita precisamente durante el reinado conjunto de Tutmés III-Hatshepsut a través de ejemplos como la presente composición o de otras similares a través de un repertorio de expresio[210] nes e ideas bien establecidas en los protocolos funerarios y religiosos de la elite -que sugieren una existencia previa de esa tendencia-y, quizás también, en sus propios sentimientos de piedad personal ${ }^{15}$.

\section{El ámbito formal $o$ artístico}

Los himnos criptográficos también han de insertarse en el contexto artístico-gráfico del período que, como en el caso de la Hochkultur egipcia, se basa en la permanente dialéctica entre innovación y arcaísmo que tiene lugar a lo largo de la historia de la civilización faraónica. Sin duda alguna el mejor ejemplo en el período aquí tratado de la complementariedad entre ambas tendencias contrapuestas y, a la vez, complementarias es el templo "de millones de años" de la reina Hatshepsut en Deir el-Bahari. Realizado siguiendo modelos arquitectónicos del pasado tebano (concretamente las tumbas-saff de los reyes del inicio de la dinastía XI y, sobre todo, el epígono hiperdesarrollado de este modelo que es el complejo "funerario" de Mentuhetep II) y decorado con temas y escenas inspirados o copiados de los complejos funerarios de los Reinos Antiguo y Medio, ese santuario es, paradójicamente, uno de los logros más originales de la arquitectura egipcia y, también, uno de los templos conocidos que ofrecen un programa iconográfico más innovador ${ }^{16}$.

En concreto, los himnos de Djehuty en su aspecto meramente formal tienen más que ver con las innovaciones culturales desarrolladas en este período que con sus aspectos arcaizantes. Ya el solo hecho de que aparezcan en un temprano y raro ejemplo de decoración compleja y elaborada al exterior de una capilla funeraria los hace excepcionales. Si a ello se les suma que se trata de unos de los primeros ejemplos conocidos de criptografía "normal" u "ordinaria", se convierten en un hito muy significativo para comprender los logros y el desarrollo de la cultura cortesana tebana al inicio de la dinastía XVIII. Este tipo de

13. Posener, 1975; Baines, 1991: 174-186.

14. Assmann, 1995: 102-132.

15. Stewart, 1964; Stewart, 1967. En la jamba izquierda de la entrada de la tumba de Djehuty quedan restos de otro himno solar de contenido similar.

16. Sobre el espíritu conservador e innovador de este reinado, véase, respectivamente, Roth, 2005; Callender, 2002. 
escritura ya aparece durante el Reino Medio en forma de algunos signos insertados dentro de los textos jeroglíficos convencionales ${ }^{17}$. El primer ejemplo conocido de composición íntegramente criptográfica que utiliza este código (una rúbrica en el llamado Papiro matemático Rhind) es un poco más tardío datando del final de la dinastía $\mathrm{XV}^{18}$. Los himnos de Djehuty no son, por tanto, los más antiguos aunque sí son los primeros conocidos en un ámbito funerario privado $\mathrm{y}$, también, pese a su antigüedad, son uno de sus ejemplos más extensos. Por tales características es posible que, viendo que la criptografía ordinaria siguió unos códigos más o menos fijos pero lo suficientemente libres como para dejar que cada escriba trocara el valor de los signos o crease nuevos grafemas, los textos de Djehuty supusieran, en solitario o formando parte de una tendencia más general de ese período, un importante hito en el desarrollo de ese tipo de escritura.

Su aparición coincide con cierto desarrollo -hay que recordar que este fenómeno de la escritura es un fenómeno marginal y elitista- de otras formas de criptografía que se van a dar justo antes del reinado conjunto de Tutmés III-Hatshepsut y, sobre todo, durante el mandato conjunto de ambos reyes. En el ámbito oficial, las primeras evidencias de fórmulas criptográficas parecen documentarse bajo Tutmés I al que, con frecuencia, la soberana volverá su vista imitando algunos aspectos de su política y de sus logros artísticos ${ }^{19}$. Durante la regencia y reinado de Hatshepsut se observa con mayor claridad la búsqueda de formas de expresión criptográficas tanto en el ámbito oficial como privado. Dentro del primero cabe destacar su uso en la cuarta y quinta hora de El Amduat, una composición funeraria restringida a la realeza que comienza a inscribirse en este momento en las tumbas de Hatshepsut (?), Tutmés I y Tutmés III (KV 20 (?); KV 38 y KV 34 respectivamente) ${ }^{20}$. En esa dimensión el exponente más paradigmático de esta proliferación de este tipo de escritura "enigmática" es, sin duda, el denominado criptograma del praenomen de la reina y, también, aunque en menor medida, el del praenomen de Tutmés III ${ }^{21}$. La creación de estos emblemas, quizás inspirados en ejemplos anteriores -aunque usando jeroglíficos convencionales- en soportes tan dispares como la joyería ${ }^{22}$, dio pie a la experimentación por parte de algunos particulares de fórmulas similares mucho más sofisticadas (y quizás por ello menos exitosas) como se observa en los criptogramas con el nomen y praenomen de la reina creados por Senenmut y que éste hizo inscribir en varias de sus estatuas-cubo refiriéndose a ellas como "las imágenes que hice como un producto de mi corazón como quien trabaja en el campo (i.e. como fruto de mi propio esfuerzo) sin que los encontrase en los escritos de los antepasados" ${ }^{23}$.

17. Véanse algunos ejemplos en Darnell, 2004: 23, n. 41.

18. Para el papiro, BM EA 10058, véase Morenz, 1996: 193-197.

19. Para la criptografía durante este período, véase Drioton, 1940: 377-383; Krauss, 1992: 86-87, fig. 3 (Cairo TR 27|3|25|4).

20. Resulta difícil precisar cuándo fue construida la KV 38 destinada a Tutmés I. Si es la tumba del rey citada por Ineni, tal y como cree Roehrig, 2005: 185-186, sus ejemplares de El Amduat serían los más antiguos. Es posible, sin embargo, que fuera realizada por Tutmés III, véase al respecto Reeves y Wilkinson, 1996: 95, teniéndose que datar, de este modo, dicha composición después de los ejemplos situados en la tumba real de Hatshepsut. Hornung, 1987: X, sin embargo cree que hay cierta confusión en relación con los textos de El Amduat de la KV 20 y la KV 38, y que, en realidad, sólo la KV 38 estuvo decorada con ese libro.

21. Para el criptograma de la reina véase, por ejemplo, Drioton, 1938: 238-245; Robins, 1999: 108-110; para el del rey véase Ricke, 1939: lám. 1 (b).

22. Véase, por ejemplo, Londres BM 54460, con el praenomen de Senusert II; Andrews, 1981: $74-75$ (554), láms. 30-31, donde también se ofrecen otros posibles paralelos.

23. Drioton, 1938; Keller, 2005 b: 117. 
Dentro de ese ámbito privado (privado más por el público al que estaba destinado que por quienes lo producían, quizás factorías de la Corona) habría que sumar otros ejemplos peor conocidos pero que son significativos por su difusión. Es el caso de diferentes fórmulas criptográficas inscritas en algunos escarabeos de este reinado. Entre ellos, además de la presencia del criptograma de la reina, destacan los trigramas de Amón que quizás fueran creados $-\mathrm{o}$, al menos, popularizados- en este momento ${ }^{24}$. Se trata de composiciones "enigmáticas" del nombre de dicho dios que tuvieron un gran éxito en períodos posteriores ya que daban, a través de un ingenioso retruécano gráfico, un poder especial al nombre del dios que significaba "el oculto".

En conjunto, estos ejemplos, aunque escasos en número, muestran el interés de la intelligentsia egipcia por nuevas e ingeniosas formas de expresión, algo que también se observa en el propio repertorio iconográfico de las capillas funerarias de este período que comienzan a incorporar nuevos temas como la llegada de tributos extranjeros o los regalos ofrecidos al rey durante el año nuevo o con motivo de su coronación.

La criptografía puede verse, pese a ser un aspecto muy secundario, como un significativo síntoma de ciertas tendencias innovadoras -que suelen ir acompañadas de otras arcaizantes- en el arte y en la cultura de determinados reinados. Es el caso, como se ha visto, del gobierno conjunto de Tutmés III-Hatshepsut, y, también, de aquél de Amenhetep III, en donde, además del empleo de un criptograma real similar al de la reina, se observan importantes ejemplos de criptografía privada que suelen ir acompañados también de la manifestación por parte de sus autores de conocimientos restringidos o, también, de búsqueda de documentación y tradiciones pasadas ${ }^{25}$.

\section{Funciones de los himnos}

Situados dentro de un Sitz im Leben genérico, es necesario volver a las composiciones religiosas de Djehuty e intentar definir sus funciones precisas tanto en el plano religioso como, también, en el social y cultural más cercano a su propietario. Todos ellos, como se verá, están, como sucede con todas las facetas de la civilización egipcia, estrechamente imbricados.

Respecto a sus funciones religiosas y al empleo de la criptografía en ellos, conviene separar diferentes aspectos. En primer lugar, los textos tienen un claro componente ritual. Las figuras orantes de Djehuty que los acompañaban y, también, las ofrendas que se encuentran ante ellos, muestran que eran composiciones destinadas a perpetuar la veneración del propietario a la divinidad solar y, también, a las ctónicas. En este sentido, todo el conjunto manifiesta, como ya se ha indicado anteriormente, la piedad personal de Djehuty expresada a través tanto de una relación de do ut des (formulada de forma explícita al final del "himno ctónico") como, también aunque se trate sólo de una de las muchas facetas de dicha relación-, por la reivindicación de formar parte de los seguidores de Re y de Ptah. Las escenas relacionadas con estas composiciones contrastan en gran medida con las que aparecen justo debajo de ellas en donde Djehuty no es ya sujeto del culto sino objeto del mismo, al mostrarse como destinatario de ciertas ofrendas $\mathrm{y}$ ritos funerarios.

24. Drioton, 1957, retrotrae, quizás exageradamente, hasta el Reino Antiguo el uso de estos trigramas. Sobre su difusión en este momento, véase Hornung y Staehelin, 1976: 173.

25. Es el caso del criptograma del praenomen del rey, que aparece en su templo en Luxor, de numerosos textos criptográficos privados de sus contemporáneos (véase Drioton, 1933: 2-14 (A); 20-34 (C-E)); del desarrollo de técnicas como los crosswords hymns (tumba de Jeruef, TT 192); o de la mención por este mismo personaje de la celebración del festival Sed siguiendo tradiciones antiguas (Urk. IV 1867, 13-18). 
El empleo en estos himnos de este tipo de escritura "enigmática" podría haber buscado, en paralelo a las funciones citadas arriba, la potenciación de su eficacia. El hecho de que en egipcio la palabra que sirve para expresar la descodificación de la criptografía es whe, "pescar, capturar, desanudar", parece indicar que el ejercicio de lectura de estos textos por escribas más o menos capaces podría "liberar" o "activar" sus contenidos haciéndolos más eficientes (un buen ejemplo de ello son los trigramas de Amón) y, a la vez, beneficiando con el favor divino a quienes eran capaces de leerlos ${ }^{26}$. Quizás por este mismo motivo las composiciones criptográficas, como bien ha indicado Darnell, estén en relación con espacios liminales (por ejemplo, jambas de puertas en templos). Su comprensión y "desciframiento" podría ser una forma simbólica del acto de “abrir" puertas o superar obstáculos. Al igual que en ultratumba, donde el difunto debía recitar diferentes conjuros para ingresar en estancias o salvar dificultades, los himnos de Djehuty pudieron ser, entre otras funciones, una llave de acceso de los visitantes al monumento (la puerta de la capilla está justo a su derecha). Igualmente la acción de "desanudar" el contenido de los textos suponía una acción regenerativa que potenciaría el contenido y finalidad de los dos himnos y que también se aprecia, tal y como ha observado Hornung, en el uso de este tipo de escritura en los capítulos IV y V de El Amduat, precisamente en el momento crítico y fundamental de la regeneración de la divinidad solar ${ }^{27}$.

En un plano que se podría calificar como "mundano", los criptogramas de la TT11, en la parte más visible y visitada de su monumento funerario, serían una buena tarjeta de presentación del ingenio, erudición e innovación de su propietario. Fuese él, o no, su creador (sobre esto se volverá más abajo), su presencia en la tumba era sólo uno más entre diferentes elementos tumbales que manifestaban, al menos ante el visitante con cierta cultura, los gustos exigentes y conocimientos profundos de Djehuty. Esto ya se observa, a primera vista, en las dimensiones, aparentemente extraordinarias de su patio o en la decoración, refinada y monumental, emplazada en él. Una vez dentro, quien entrara en la capilla tendría acceso a una de las versiones más completas y antiguas conocidas del ritual de la apertura de la boca y, en la sala interior, a un extraño grupo de ceremonias, aún por bautizar, con unas características que se antojan arcaizantes y que sólo son conocidas en otros dos monumentos funerarios de la necrópolis tebana, aquéllos de Montuherkepeshef (TT 20) y de Amenemipet (TT 29) ${ }^{28}$.

Esta exhibición de la accesibilidad de Djehuty a determinados conocimientos religiosos y, también, a su capacidad para incluirlos en su capilla, estaba acompañada por otros pequeños recursos gráficos ingeniosos, aunque no excepcionales, como era el uso en la estela de Northampton de una combinación de líneas de escritura en horizontal con otras que, a modo de mesósticos y teleósticos, las interrumpen verticalmente, o bien la presencia de unos peculiares títulos religiosos en las jambas de acceso a la sala interior.

En conjunto, todos estos elementos desempeñaban simultáneamente dos importantes

26. De este modo, en un himno criptográfico del reinado de Amenhetep III, el difunto se dirige a "todos los escribas que conocéis vuestra función, que ponéis vuestro corazón para interpretar/desanudar (las cosas) que están ocultas" (wḥ imn.w), véase Drioton, 1933: 26. Para el verbo, véase Russo Abd el-Samie, 2002: 36-42.

27. Hornung, 1963: 90; véase también, para otros usos de la criptografía con ese sentido, Darnell, 2004: 479-480.

28. Para estas escenas, véase Davies, 1913: láms. VI-XI; XIV; XVI (Montuherjepeshef); XLIII (Amenemipet). La tumba de este último está siendo actualmente excavada por una misión de la Universidad Libre de Bruselas. Un fragmento de estas escenas procedente de la primera tumba ha sido encontrado en el interior del monumento de Djehuty, quizás depositado durante las excavaciones del Marqués de Northampton o en intervenciones posteriores. 
funciones: la esencial de convertir la capilla en una "máquina" con destino al Más Allá lo más eficiente posible y la no menos desdeñable de hacer de ella un monumento llamativo y destacado dentro del paisaje, quizás ya superpoblado, de la necrópolis tebana. El hecho de que en este momento otros nobles como Senenmut, Hapuseneb, Useramón o Puyemre ${ }^{29}$, por poner los ejemplos más conocidos, buscaran destacar sus sepulcros dotándolos de contenidos singulares o soluciones arquitectónicas, paisajísticas o artísticas monumentales y/o originales, permite suponer que Djehuty, cuya tumba, a excepción del patio, era de dimensiones más modestas, intentara hacerla destacar equipándola con textos e imágenes especiales expresados de forma particular que a su vez le servirían para ensalzar su propia figura y la de su linaje ${ }^{30}$. Esa combinación de las funciones religiosas y de prestigio del mausoleo quizás sea mencionada en un pasaje de la estela con el himno a Amón-Re que Djehuty emplazó en la fachada de su sepulcro: "que tú (=Amón-Re) dispongas que mi capilla funeraria $\left((m)^{\complement} h^{\complement} t\right)$ esté abierta eternamente y que permanezca de acuerdo a tus favores/dádivas" ${ }^{31}$.

El emplazamiento del monumento funerario en Dra Abu el-Naga y no en Sheij Abd el-Gurna, donde parecen haberse situado las capillas más prominentes, podría explicarse por muy diferentes motivos (propiedades o sepulcros familiares en el área, proximidad al hogar familiar, etc). Fuesen cuales fuesen las razones, su localiza- tratarse del solar de la necrópolis real de la dinastía XVII y, quizás, de los primeros reyes de la dinastía XVIII, pudo deberse -entre otros motivos- a esa búsqueda de prestigio y de significar el monumento en un paisaje determinado (su cercanía al de Heri, TT 12, uno de los sepulcros privados tebanos con decoración en relieve más antiguos que se conocen del Reino Nuevo podría ser otro motivo añadido) $)^{32}$. La tumba de Djehuty, de hecho, pudo dejar sobre otros hipogeos realizados en su entorno ciertas improntas. No debe de ser casualidad que muy cerca de la TT 11, Parennefer, un contemporáneo de Horemheb, incluyera, varios siglos después, textos criptográficos de contenido similar acompañados también por figuras orantes en las jambas de la puerta de acceso a su capilla ${ }^{33}$ o que, quizás (no se sabe si poco antes o después o simultáneamente a Djehuty), Mentuherjepeshef (el propietario de la TT 20) también incluyera en su construcción funeraria los mismos rituales arcaicos que se encuentran en el de Djehuty ${ }^{34}$.

Situándonos en este contexto de exhibición artística y monumental de la originalidad y del conocimiento de los nobles, conviene reconsiderar qué fue, en realidad, la escritura criptográfica en la cultura egipcia. El calificativo de esta escritura como "enigmática" o "criptográfica" parece poco acertada ya que son numerosos sus ejemplos que por su contenido o su emplazamiento muestran que lo último que buscaron los escribas que las desarrollaron fue el ocultar a sus contemporáneos sus temas, en muchos casos banales. En

29. Para una introducción a la corte real durante el reinado conjunto de Tutmés III-Hatshepsut, véase Bryan, 2005 y, en menor medida, Keller, 2005a.

30. Para un estudio de la función social y conmemorativa de las tumbas en este período, véase Dorman, 2003.

31. Urk. IV 446, 8-9.

32. Dicha tumba también es objeto de estudio y excavación por la misión española del "Proyecto Djehuty".

33. Es la tumba -161-, según Kampp, 1996: 713-716; para los textos véase Kampp, 1994: 185-186, lám. 26 (b); Darnell, 2004: 21-27, lám. 1 (B-E).

34. Davies, 1913. Ambas tumbas tiene numerosos puntos en común como el estilo, los paralelos decorativos, la propia decoración de las jambas de entrada o del corredor. Todo ello permite pensar en que se realizaron en un momento muy cercano la una de la otra y, también, que una de ellas influyó profundamente en la otra. 
el caso concreto de Djehuty, la ubicación de los himnos en el lugar más público del espacio de su monumento funerario contradice por completo una supuesta intención secretista o esotérica. La realización de estas composiciones religiosas con criptogramas debió de buscar, como ya se ha indicado, la potenciación mágica de sus contenidos pero, también, aunque resulte paradójico, la búsqueda de público. Como han indicado autores como Darnell o Baines, la criptografía debió de tener una finalidad contraria a lo que indica su calificativo actual como "enigmática" ${ }^{35}$. Esta forma de expresión escrita sería, en realidad, una forma de enfatizar o llamar la atención a los potenciales lectores sobre el contenido del texto. Este hecho es evidente, por ejemplo, en su uso en los nombres de ciertos individuos o en fórmulas tan frecuentes como el htp di ny-swt. Es probable que la criptografía no fuera un obstáculo insalvable para los escribas mínimamente avezados. De este modo, el fenómeno criptográfico debería de entenderse más bien, dejando a un lado su aspecto mágicoreligioso, como una práctica lúdico-poética de la escritura en la que sus redactores y sus lectores entablarían un diálogo basado tanto en el juego e ingenio, como también en la búsqueda de nuevas fórmulas, originales y "bellas", para la expresión escrita de las ideas ${ }^{36}$.

\section{DJEHUTY CRIPTÓGRAFO}

Para terminar esta breve contextualización de los himnos criptográficos de la TT11, queda por indagar sobre la posible autoría de las composiciones. Resulta obvio que es imposible afirmar o negar que su concepción y elaboración fueran obra del propietario de la tumba pero, al menos, se puede vislumbrar si fue posible o no tal probabilidad. En este sentido Djehuty pudo ser perfectamente su creador. En las paredes de su monumento funerario fue calificado como "escriba" y "escriba excelente" (žs $i k r)$ " . Por otro lado, su nombre, un nisba teóforo que significa "el de Thot", y los cargos de "supervisor de los sacerdotes en Hermópolis (imy-r hm.(w)-ntr $m$ hmmw)"38 y de "grande de los cinco en el templo de Thot (wr 5 n pr dhwty)" ${ }^{\prime 39}$, sugieren un vínculo especial de este personaje con la provincia de la que el dios de la escritura fue la divinidad principal del panteón local y en donde, desde el Segundo Período Intermedio, se emplazaron algunos hallazgos de textos religiosos antiguos ${ }^{40}$. Su capacidad como escriba, además, se hace patente en el templo de Deir el-Bahari, donde la figura, cancelada, que representa al amanuense que registra la medida de los aromata de Punt, parece haber sido la suya ${ }^{41}$.

Dejando a un lado estos indicios, dos epítetos inscritos en su capilla también sugieren su acceso a conocimientos restringidos y, también, su capacidad por entender ciertos tipos de documentos que bien podrían ser criptográficos. El primero, "quien conoce cada secreto del palacio $(r h(w) s s ̌ t 3 n b n ` h)$ ", es el menos preciso ya que "los secretos" podrían ser tanto documentos reservados como, también, cotilleos o confidencias del

35. Baines, 1983: 581-582; Darnell, 2004: 471-473.

36. Sobre el aspecto "poético", esto es, creativo y original, en la grafía jeroglífica, véanse Morenz, 2004; Morenz, 2008.

37. Urk. IV 427, 12; 448, 4, 5.

38. Urk. IV 421, 7.

39. Título no recogido por Sethe.

40. Sobre estos hallazgos, en rúbricas en algunas versiones de la dinastía XVIII de las recitaciones $30 \mathrm{~B}, 64$ y 148 de $E l$ libro de los muertos, que están datados en el reinado de Menkaure y atribuidos a Hordjedef, véase Wildung, 1969: 217-221 (Dok. XXIV. 60).

41. Véase la lectura del relieve realizada por Howard Carter en Naville, 1898: lám. 79. 
palacio. El segundo, "quien entiende los escritos de la casa oculta $\left(\left[w h{ }^{\top}\right] w[d] r f . w n(y) . w p r h 3[p]\right)$ ", es mucho más revelador. Ya me he referido al significado de $w h^{\top}$ como el verbo egipcio usado para referirse al desciframiento de los criptogramas, por lo cual este epíteto, siempre y cuando la reconstrucción que hace Sethe de la parte perdida del texto sea cierta, podría referirse claramente al conocimiento de ese tipo de escritura $\mathrm{y}$, también, a los contenidos de "los escritos de la casa oculta", una institución desconocida hasta el momento pero que parece aludir, por su nombre, a un lugar donde se guardaban documentos de carácter restringido ${ }^{42}$. 


\section{Bibliografía}

Andrews, C.A.R.

1981 Catalogue of Egyptian Antiquities in the British Museum. VI. Jewelllery I. From the earliest Times to the Seventeenth Dynasty. London.

Assmann, J.

1983 Sonnenhymnen in Thebanischen Gräbern. Mainz am Rhein.

1995 Egyptian Solar Religion in the New Kingdom. Re, Amun and the Crisis of Polytheism. London.

1999 Ägyptische Hymnen und Gebete. FreiburgGöttingen.

BAINES, J.

1983 Literacy and Ancient Egyptian Society, Man n.s. 18: 572-599.

1990 Restricted Knowledge, Hierarchy and Decorum: Modern Perceptions and Ancient Institutions, JARCE 27: 1-23.

1991 Society, Morality, and Religious Practice, en Shafer, B.E. (ed.): Religion in Ancient Egypt. Gods, Myths and Personal Practice, Ithaca - London: 123-200.

BarucQ, A.; Daumas, F.

1980 Hymnes et prières de l'Égypte ancienne. Paris.

BRIAN, B.M.

2005 Administration in the Reign of Thutmose III, en Cline, E.H. y O'Connor, D. (eds.): Thutmose III. A New Biography, Ann Arbor: 69-122.

Callender, V.G.

2002 The Innovations of Hatshepsut's Reign, $B A C E$ 13: 29-46.

DARNELL, J.

2004 The Enigmatic Netherworld Books of the Solar-Osirian Unity. Cryptographic Compositions in the Tombs of Tutankhamun,
Ramesses VI and Ramesses IX. FreiburgGöttingen.

Davies, N. DE G.

1913 Five Theban Tombs. London.

1923 The Tomb of Puyemrê at Thebes. Volume II: The Chapels of Hope. New York.

Diego Provencio, A.M a . De

2003 Autobiografía de Djehuty: La "Estela de Northampton", BAEDE 13: 117-132.

DIJK, J. VAN

2005 Early Christian Apochrypha and the Secret Books of Ancient Egypt, en Hilhorst, A. y Hooten, G.H. van (eds.): The Wisdom of Egypt. Jewish, Early Christian, and Gnostic Essays in Honour of Gerard P. Luttikhuizen, Leiden: 419-428.

DORMAN, P.F.

2003 Family Burial and Commemoration in the Theban Necropolis, en Strudwick, N. y Taylor, J. H. (eds.): The Theban Necropolis. Past, Present and Future, London: 30-41.

Drioton, E.

1933 Essai sur la cryptographie privée de la fin de la XVIII ${ }^{\mathrm{e}}$ dynastie, $R d E$ É 1: 1-50.

1934 La cryptographie égyptienne, Revue Lorraine d'Anthropologie 6: 5-28.

1938 Deux cryptogrammes de Senenmout, ASAE 38: 231-246.

1940 Recueil de cryptographie monumentale, ASAE 40: 305-429.

1953 Les principes de la cryptographie égyptienne, $C R A I B L$ 1953: 355-365.

1957 Trigrammes d'Amon, WZKM 54: 11-33.

DziobeK, E.

1994 Die Gräber des Vezirs User-Amun. Theben Nr. 61 und 131. Mainz am Rhein. 
GALÁn, J.M.

2006 En busca de Djehuty. Crónica de una excavación arqueológica en Luxor. Barcelona.

2007 The Tombs of Djehuty and Hery (TT 11-12) at Dra Abu el-Naga, en Goyon, J.-C. y Cardin, Ch. (eds.): Proceedings of the Ninth International Congress of Egyptologists, Louvain: 777-787.

Hornung, E.

1963 Das Amduat, die Schrift ds verborgenen Raumes. Band I. Wiesbaden.

1987 Texte zum Amduat. Teil I: Kurzfassung und Langfassung, 1. bis 3. Stunde. Geneva.

Hornung, E.; Staehelin, E.

1976 Skarabäen und andere Siegelamulette aus Basler Sammlungen. Mainz am Rhein.

KAHL, J.

1996 Steh auf, gib Horus deine Hand. Die Überlieferungsgeschichte von Altenmüllers Pyramidentext - Spruchfolge D. Wiesbaden.

KAMPP, F.

1994 Vierter Vorbericht über die Arbeiten des Ägyptologisches Instituts der Universität Heidelberg in thebanischen Gräbern der Ramessidenzeit, MDAIK 50: 175-188.

1996 Die thebanische Nekropole zum Wandel des Grabgedankens von der XVIII. bis zur XX. Dynastie. Mainz am Rhein.

[218]

KARKOWSKI, J.

2003 Deir el-Bahari VI. The Temple of Hatshepsut. The Solar Complex.

Warsaw.

Keller, C.A.

2005a The Royal Court, en: Roehrig (ed.) 2005: 101-106.

2005b The Statuary of Senenmut, en Roehrig (ed.) 2005: 117-131.
Krauss, R.

1992 Das Kalendarium des Papyrus Ebers und seine chronologisches Verwertbarkeit, Ä\&L 3: 75-96.

LOUANT, E.

2000 Comme Pouiemrê triompha de la mort. Analyse du programme iconographique de la tombe thébaine $n^{\circ} 39$. Louvain.

Morenz, L.

1996 Beiträge zur Schriftlichkeitskultur im Mittleren Reich und in der 2. Zwischenzeit. Wiesbaden.

2004 Visuelle Poesie al seine sakrale ZeichenKunst der altägyptischen hohen Kultur, SAK 32: 311-326.

2008 Sinn und Spiel der Zeichen. Visuelle Poesie im Alten Ägypten. Köln.

NAVILLE, E.

1898 The Temple of Deir el Bahari. Plates LVI - LXXXVI. End of the Northern Half and Southern Half of the Middle Platform. London.

1901 The Temple of Deir el Bahari. Part IV. Plates LXXXVII - CXVIII. The Shrine of Hathor and the Southern Hall of Offerings. London.

Posener, G.

1975 La piété personnelle avant l'âge amarnien, $R d E$ 27: 195-210.

ReEves, N.; WiLKInson, R.H.

1996 The Complete Valley of the Kings. Tombs and Treasures of Egypt's Greatest Pharaohs. London.

RicKe, $\mathrm{H}$.

1939 Der Totentempel Thutmoses III. (B̈̈BA3). Kairo.

Robins, G.

1999 The Names of Hatshepsut as King, JEA 85: 103-112. 
RoEHrig, C.H. (ED.)

2005 Hatshepsut. From Queen to Pharaoh. New York, New Haven \& London.

Roehrig, C.H.

2005 The Two Tombs of Hatshepsut, en Roehrig (ed.), 2005: 184-189.

Rотн, A.M.

2005 Hatshepsut's Mortuary Temple at Deir elBahri. Architecture as Political Statement, en Roehrig (ed.), 2005: 147-150.

Russo Abd el-SAmie, B.

2002 Due frammenti di stele votive da Gebelein, Aegyptus 82: 27-45.

Sethe, K.

1908 Die Aenigmatischen Inschriften, en
Northampton, Marquis of; Spiegelberg, W. y Newberry, P.E.: Report on some Excavations in the Theban Necropolis during the Winter of 1898-1899, London: $4 *-12 *$.

STEWART, H.M.

1964 Egyptian Funerary Statuettes and the Solar Cult, Bulletin of the Institute of Archaeology 4: 165-170.

1967 Traditional Sun Hymns of the New Kingdom, Bulletin of the Institute of Archaeology 6: 29-74.

WILDUNG, D.

1969 Die Rolle ägyptischer Könige im Bewusstein ihrer Nachwelt. Teil I. Potshume Quellen über die Könige der ersten vier Dynastien. Berlin. 


\section{Trabajos de Egiptología Papers on Ancient Egypt}

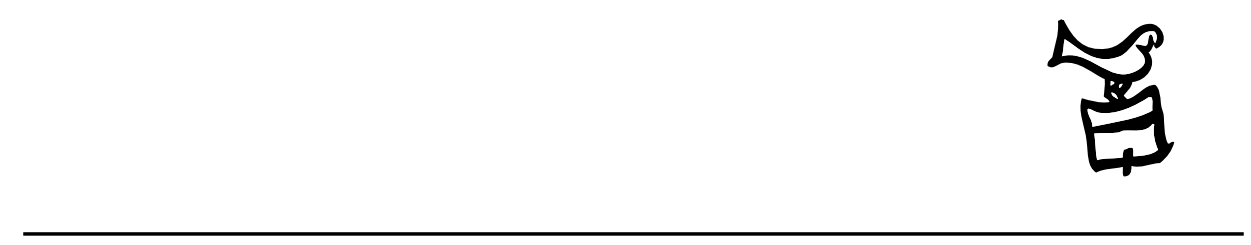

Número 5/1 2009 


\section{Actas \\ III Congreso Ibérico de Egiptología III Congresso Ibérico de Egiptologia}

Editores

Miguel Ángel Molinero Polo Covadonga Sevilla Cueva 


\title{
Editor
}

Miguel Ángel Molinero Polo

Universidad de La Laguna

\section{Consejo Editorial}

\author{
Antonio Pérez Largacha \\ Universidad de Castilla-La Mancha \\ José-R. Pérez-Accino \\ Birkbeck, Universidad de Londres \\ Covadonga Sevilla Cueva \\ Universidad Autónoma de Madrid
}

\section{Comité Científico}

Josep Cervelló i Autuori

Universitat Autònoma de Barcelona

$\mathrm{M}^{\mathrm{a}}$ José lópez Grande

Universidad Autónoma de Madrid

Josep Padró i Parcerisa

Universitat de Barcelona

$\mathrm{M}^{\mathrm{a}}$ Carmen Pérez Die

Museo Arqueológico Nacional, Madrid

Ester Pons Mellado

Museo Arqueológico Nacional, Madrid

José M. Serrano Delgado

Universidad de Sevilla

\section{Colaboradores Editoriales}

Linda Steynor

English editorial assistant

Hervé Mouriacoux

Assistant éditorial pour la langue française 
Trabajos de Egiptología está producida por Isfet. Egiptología e Historia c/ Blanco $1,2^{\circ}$

38400 Puerto de la Cruz

Tenerife-Islas Canarias

España

Maquetación: Proyecto Limón

(C) Autores de los artículos aparecidos

y Consejo Editorial de Trabajos de Egiptología - Papers on ancient Egypt

Depósito Legal: TF-2302-2009

ISSN: $1695-4750$

Imprime: Gráfica Los Majuelos, S.L.L.

imprenta@graficaslosmajuelos.com

Tfno.: 922311455 


\section{Comité Científico \\ III Congreso Ibérico de Egiptología III Congresso Ibérico de Egiptologia}

Miguel Á. Molinero Polo

Universidad de La Laguna

Presidente del Comité Organizador del III Congreso Ibérico de Egiptología

Miembro del Comité Organizador del I Encuentro de Egiptología

Josep Cervelló Autuori

Universitat Autònoma de Barcelona

Presidente del Comité Organizador del II Congreso Ibérico de Egiptologia

José Manuel Galán Allué

Consejo Superior de Investigaciones Cientificas

Director del Proyecto Djehuty, Luxor, Egipto

$\mathrm{M}^{\mathrm{a}}$ Helena Trindade Lopes

Universidad de Lisboa

Directora de la Misión Arqueológica Portuguesa en Menfis

Josep Padró i Parcerisa

Universitat de Barcelona

Director de la Misión Arqueológica de Oxirrinco

Antonio Pérez Largacha

Universidad de Castilla - La Mancha

Miembro del Comité Organizador del I Encuentro de Egiptología

José Ramón Pérez-Accino

Birkbeck College, University of London

Miembro del Comité Organizador del I Encuentro de Egiptología

$\mathrm{M}^{\mathrm{a}}$. Carmen Pérez Díe

Museo Arqueológico Nacional

Directora de la Misión Arqueológica Española en Heracleópolis Magna, Egipto

Covadonga Sevilla Cueva

Universidad Autónoma de Madrid

Miembro del Comité Organizador del I Encuentro de Egiptología 